\title{
PEMBENTUKAN PORTOFOLIO SAHAM DENGAN MENGGUNAKAN METODE MODEL INDEKS TUNGGAL DAN SECARA ACAK PERIODE PENELITIAN JANUARI 2013-DESEMBER 2017
}

\author{
Andini Nurwulandari \\ Universitas Nasional Jakarta \\ Email: andinmanajemen@gmail.com
}

\begin{abstract}
Abstrak
Portofolio dapat dilihat sebagai kumpulan investasi dan kepemilikan berbagai aset oleh investor, baik individu maupun institusi. Analisis ini menggunakan pendekatan analitik kuantitatif dan deskriptif. Data sekunder dari situs resmi kategori BEI LQ45 yang berhasil dijaring setiap bulan selama periode observasi yaitu Januari 2013-Desember 2017. Pengambilan sampel dilakukan secara acak. Hasil temuan studi ini menunjukkan bahwa tiga kandidat portofolio optimal ditemukan menggunakan MIT; WIKA, ASRI, serta SMGR adalah saham portofolio yang memungkinkan. Berdasarkan data saham yang termasuk dalam perhitungan saham LQ45 periode Januari 2013-Desember 2017, dipilih secara acak dua kandidat portofolio optimal: ASRI dan SMGR. Komposisi atau proporsi dana yang diperoleh masing-masing saham optimal untuk pembentukan portofolio; terbesar adalah saham WIKA 0,559948006, dan yang terkecil adalah saham UNTR, dengan poin 0,559948006.
\end{abstract}

Kata Kunci: Portofolio, Saham, Model Indeks Tunggal.

\section{Abstract}

A portfolio is described as a collection of investments and holdings made by investors, both individuals and institutions. This analysis employs a quantitative and descriptive analytic approach. Secondary data from the IDX LQ45 category's official website, which was successfully netted each month during the observation period, namely January 2013December 2017. Random sampling was used to gather samples. The study's findings indicate that three optimal candidate portfolios were defined using a single index model; the candidate portfolio stocks are WIKA, ASRI, and SMGR. Using data from the LQ45 stock calculation for the period January 2013 to December 2017, we randomly selected two optimal portfolio candidates: ASRI and SMGR. The composition or proportion of funds obtained by each share is optimal for portfolio formation; the largest is WIKA's shares at 0.559948006 points, and the smallest is UNTR's shares at 0.559948006 points.

Keywords: Portfolio, Stock, Single Index Model.

\section{A. INTRODUCTION}

Investasi diklasifikasikan menjadi dua jenis berdasarkan bentuk asetnya: investasi real estat dan investasi aset keuangan (Sari \& Prijati, 2015). Investasi aset riil berupa perolehan aset produktif, seperti pembangunan pabrik atau pembebasan lahan (Dian, 2018). Sedangkan aset keuangan diperoleh melalui pembelian sekuritas seperti saham, saham, dan reksa dana (Afriana, Tarno \& Sugito, 2017).

Pembentukan portofolio dan pasar saham menunjukkan korelasi positif dalam jangka panjang. Namun, ada variasi waktu yang substansial dalam hubungan antara pengembalian 
saham dan obligasi dalam jangka pendek, termasuk periode korelasi negatif yang berkelanjutan (Noer, Saribanon \& Nurwulandari, 2017). Variasi waktu ini memiliki implikasi penting untuk memahami ekonomi pembentukan harga obligasi bersama dan mungkin memiliki aplikasi praktis dalam alokasi aset dan manajemen risiko (Kusbiantono, 2002). Gabungan dari hal tersebut tersebut dapat terdiri dari aset fisik, aset keuangan, atau kombinasi keduanya. Di pasar modal, dana dikaitkan dengan portofolio aset keuangan, khususnya, campuran dari banyak sekuritas, dengan tujuan untuk memaksimalkan pengembalian sekaligus meminimalkan risiko (Savitriani \& Sugiyono, 2017).

Memiliki portofolio yang tidak terdiversifikasi akan membuat individu menghadapi risiko non-sistematis yang tidak perlu, yang dapat dikurangi melalui diversifikasi portofolio sederhana. Dalam keuangan standar, investor diasumsikan membangun portofolio yang konsisten dengan prinsip integrasi aset. Fokusnya tidak hanya pada karakteristik risiko/pengembalian aset individu, tetapi bagaimana aset tersebut berinteraksi dengan posisi portofolio lainnya. Aset prospektif harus dipilih dengan membandingkan distribusi pendapatan yang dihasilkan dari pengintegrasian prospek ini dengan aset lainnya.

Dalam portofolio, risk dapat diminimalisir dengan mendiversifikasi jenis aset dalam portofolio, jumlah pengembalian yang diproyeksikan dapat ditingkatkan jika fluktuasi harga aset gabungan berbeda (Zulfa, 2015). Setiap keputusan investasi harus dibingkai dalam perspektif portofolio (Nuryana, 2014). Tidaklah cukup hanya mengetahui karakteristik dari investasi potensial itu sendiri; seseorang harus menyadari bagaimana investasi berdampak pada karakteristik risiko dan pengembalian dari keseluruhan portofolio (Irfan, 2018). Aset dievaluasi tentang bagaimana mereka bisa masuk ke dalam portofolio yang memenuhi tujuan dan batasan investor (Laksono, 2004).

Berbeda dengan keuangan standar, keuangan perilaku mengasumsikan investor membangun portofolio melalui pemisahan aset. Alih-alih mengevaluasi dampak investasi pada posisi portofolio secara keseluruhan, investor fokus pada karakteristik aset yang berbeda (Sakti \& Surepno, 2018). Investor cenderung mengevaluasi pilihan investasi satu per satu dan bukan sebagai bagian dari portofolio agregat. Investor membangun portofolio sebagai piramida aset. Setiap lapisan membawa sikap yang berbeda terhadap risiko dan disusun untuk membentuk portofolio investasi (Sunaryo, 2017).

Selain itu, teori portofolio menekankan pentingnya mempertimbangkan risiko dan pengembalian saat membangun portofolio, dengan asumsi bahwa metode formal untuk menghitung keduanya ada. Dalam bentuk yang paling sederhana, teori portofolio diinisiasi dengan mengasumsikan bahwa pengembalian efek di masa depan dapat dihitung dan kemudian menghitung risiko dengan memodifikasi distribusi pengembalian (Afriana, Tarno $\&$ Sugito, 2017). Teori portofolio menciptakan hubungan linier antara risiko dan laba atas banyak asumsi (Gudono, 2018).

Investasi saham dianggap sebagai bentuk investasi yang paling berisiko dibandingkan dengan jenis investasi lain seperti obligasi dan deposito (Hiendarto \& Indrawati, 2015). Hal ini karena antisipasi pendapatan dari berinvestasi pada sekuritas tidak dapat diprediksi, karena dividen dan capital gain termasuk dalam pendapatan saham (Paranjape \& Deshpande, 2013). Pembayaran dividen bergantung pada kemampuan perusahaan untuk memperoleh profit, sementara itu capital gain bergantung pada fluktuasi harga pada saham (Chapple \& Humphrey, 2014). Ada dua jenis faktor yang mempengaruhi tingkat risiko investasi saham: 
faktor makroekonomi dan mikroekonomi. Faktor makroekonomi adalah faktor yang mempengaruhi semua bisnis atau sektor. Pengaruh mikro, di sisi lain, sangat spesifik dan hanya berdampak pada beberapa bisnis atau sektor (Arabi, 2014).

\section{B. METODE}

Penelitian ini bersifat kuantitatif dan pendekatan deskriptif analitis. Data sekunder dari situs resmi BEI kategori LQ45 yang berhasil terjaring kontinyu selama masa periode penelitian yaitu Periode Penelitian Januari 2013-Desember 2017. Alat untuk mengumpulkan sampel adalah pengambilan sampel acak. Pendekatan yang digunakan dalam analisis ini adalah dokumentasi data. Metodologi pengujian adalah uji asumsi standar dan model uji kelayakan adalah uji F dan koefisien keputusan berdasarkan aplikasi Eview 9.

\section{HASIL DAN PEMBAHASAN}

Berikut adalah berbagai yang menjadi sampel dalam penelitian ini:

Tabel 1 Daftar Saham Perusahaan LQ45 Periode Januari 2013-Desember 2017

\begin{tabular}{|c|l|c|}
\hline No. & Kode & Company \\
\hline 1. & ASRI & Alam Sutra Realty \\
\hline 2. & BSDE & Bumi Serpong Damai \\
\hline 3. & LPKR & Lippo Karawaci \\
\hline 4. & PWON & Pakuwon Jati \\
\hline 5. & UNTR & United Tractors (Persero) \\
\hline 6. & UNVR & Unilever Indonesia \\
\hline 7. & INDF & Indofood Sukses Makmur \\
\hline
\end{tabular}

Sumber: BEI

Portofolio akan dibangun menggunakan saham perusahaan LQ45 terpilih dari Januari 2011-Desember 2015. Rumus dapat digunakan untuk mengukur variabel pasar dan saham dan untuk mengevaluasi portofolio yang optimal, hal tersebut akan menjadi MIT. Beberapa tahap harus dilakukan untuk membangun portofolio menggunakan model indeks tunggal, yaitu: menghimpun data saham untuk bisnis LQ45 dari Januari 2013 hingga Desember 2017, khususnya harga penutupan bulanan;menghitung tingkat pengembalian saham (Rit). Estimasi lengkap disertakan dalam lampiran; dan menentukan estimasi tingkat manfaat (E (Ri)).

Tabel 2 Menghitung Ri Saham LQ45

\begin{tabular}{|c|c|c|c|c|c|}
\hline \multirow{2}{*}{ Code } & \multicolumn{5}{|c|}{$\mathbf{R}_{\mathbf{i}}$} \\
\cline { 2 - 6 } & $\mathbf{2 0 1 3}$ & $\mathbf{2 0 1 4}$ & $\mathbf{2 0 1 5}$ & $\mathbf{2 0 1 6}$ & $\mathbf{2 0 1 7}$ \\
\hline ASRI & 0,669333035 & 0,30446834 & $-0,284444444$ & 0,302326682 & 0,0726 \\
\hline BSDE & 0,999998 & 0,133653043 & 0,163163163 & 0,3883348 & 0,119223583 \\
\hline LPKR & $-0,039422775$ & 0,6161616 & $-0,08$ & 0,13087712 & 0,112766077 \\
\hline PWON & $-0,563963865$ & 0,906889772 & 0,2 & 0,9084084 & $-0,032068981$ \\
\hline UNTR & 0,152570278 & $-0,25228217$ & $-0,036632885$ & $-0,087842105$ & 0,16434522 \\
\hline UNVR & 0,138383838 & 0,108042663 & 0,247112398 & 0,2408793 & 0,237391192 \\
\hline INDF & $-0,057420267$ & 0,27174813 & 0,128305129 & 0,033484843 & 0,22851952 \\
\hline ICBP & 0,113288466 & 0,6 & 0,307792409 & 0,285322733 & 0,106870338 \\
\hline WIKA & $-0,147059925$ & 1,551835148 & 0,0677578 & 1,32922383 & 0,01773045 \\
\hline INTP & 0,068967718 & 0,316716653 & $-0,1091323$ & 0,26 & $-0,07$ \\
\hline SMGR & 0,211640233 & 0,3852795786 & $-0,107266623$ & 0,15587375 & $-0,12230964$ \\
\hline JSMR & 0,226288373 & 0,298718058 & $-0,144027542$ & 0,492065593 & $-0,18894446$ \\
\hline
\end{tabular}

Sumber: data diolah 
Tabel di atas menggambarkan bagaimana return saham berubah atau berfluktuasi setiap tahun. Pengembalian saham dapat dipengaruhi oleh berbagai faktor, termasuk makroekonomi dan faktor non-ekonomi. Akan tetapi, investor fokus pada kinerja keuangan perusahaan karena dari cara pandang investor, company dengan keuangan yang kuat memberikan return yang lebih maksimal daripada perusahaan dengan kinerja keuangan yang lebih minim.

Tabel 3 Tingkat Return Pasar

\begin{tabular}{|c|c|c|c|c|c|}
\hline \multirow{2}{*}{ Bulan } & \multicolumn{5}{|c|}{$\mathbf{R m}$} \\
\cline { 2 - 6 } & $\mathbf{2 0 1 3}$ & $\mathbf{2 0 1 4}$ & $\mathbf{2 0 1 5}$ & $\mathbf{2 0 1 6}$ & $\mathbf{2 0 1 7}$ \\
\hline Januari & $-0,079486967$ & 0,033419766 & 0,031639697 & 0,044836472 & $-0,00240977$ \\
\hline Februari & 0,018954818 & 0,022040934 & 0,07551039 & 0,046692988 & 0,046247206 \\
\hline Maret & 0,070038537 & 0,03422247 & 0,030276777 & 0,033057093 & 0,013547221 \\
\hline April & 0,038416679 & 0,014357768 & 0,01993844 & 0,015073532 & $-0,079335021$ \\
\hline Mei & 0,004565447 & $-0,085517525$ & 0,00686533 & 0,022207095 & 0,026660398 \\
\hline Juni & 0,013448222 & 0,03548637 & $-0,049289734$ & $-0,003322475$ & $-0,058708683$ \\
\hline Juli & 0,063392833 & 0,047214325 & $-0,043271386$ & 0,043080408 & $-0,033019553$ \\
\hline Agustus & $-0,068879192$ & $-0,019797657$ & $-0,090088175$ & 0,00955527 & $-0,060882862$ \\
\hline September & $-0,076169644$ & 0,049806387 & 0,029964678 & 0,000150264 & $-0,06445394$ \\
\hline Oktober & 0,068136833 & 0,020681538 & 0,045051422 & $-0,00944977$ & 0,056752688 \\
\hline November & $-0,018897703$ & $-0,017055842$ & $-0,056433547$ & 0,012866775 & $-0,001916162$ \\
\hline Desember & 0,02888367 & 0,009762851 & 0,004169403 & 0,015863526 & $-0,022906202$ \\
\hline
\end{tabular}

Sumber: data diolah

Dilihat dari tabel 2 tersebut, return saham pada bulan Desember 2013 -,02888367 dan IHSG pada bulan Januari 2017 berada pada -0,00240977.

\section{Standar Deviasi}

Pengukuran standar deviasi dinyatakan sebagai berikut: $\sigma i=\sqrt{ } V a(R i)$

Tabel 4. Standar Deviasi

\begin{tabular}{|c|c|c|}
\hline Kode & Var(Ri) & Std. deviasi \\
\hline ASRI & 0,080566558 & 0,283685484 \\
\hline BSDE & 0,012535388 & 0,111916939 \\
\hline LPKR & 0,045488822 & 0,210936327 \\
\hline PWON & 0,320033378 & 0,565813954 \\
\hline UNTR & 0,024360978 & 0,156058003 \\
\hline UNVR & 0,003462086 & 0,058840988 \\
\hline INDF & 0,012204342 & 0,110573269 \\
\hline ICBP & 0,023340983 & 0,146399377 \\
\hline WIKA & 0,555306496 & 0,722807684 \\
\hline INTP & 0,029298775 & 0,170776177 \\
\hline SMGR & 0,035628856 & 0,188759989 \\
\hline
\end{tabular}

Sumber: Data diolah

Dilihat dari tabel diatas, di dapat hasil nilai standar deviasi keseluruhan diatas nol (> 0), ini menunjukan bahwa titik data individual jauh dari nilai rata-rata.

\section{Tingkat Pengembalian Risiko (Rf)}

Suku bunga bebas risiko dihitung dengan menggunakan suku bunga SBI dalam periode satu bulan, karena suku bunga SBI adalah sertifikat yang bebas risiko. Perhitungan suku bunga bebas risiko dilakukan secara bulanan yaitu dengan menghitung rata-rata 
tertimbang suku bunga SBI periode Januari 2013 sampai dengan Desember 2017.

Tabel 5 Perhitungan Tingkat Pengembalian Bebas Resiko (Rf)

\begin{tabular}{|c|c|c|c|c|c|}
\hline Bulan & $\mathbf{2 0 1 3}$ & $\mathbf{2 0 1 4}$ & $\mathbf{2 0 1 5}$ & $\mathbf{2 0 1 6}$ & $\mathbf{2 0 1 7}$ \\
\hline Januari & $6,55 \%$ & $6,25 \%$ & $5,50 \%$ & $7,25 \%$ & $7,50 \%$ \\
\hline Februari & $6,85 \%$ & $5,25 \%$ & $5,25 \%$ & $7,25 \%$ & $7,25 \%$ \\
\hline Maret & $6,85 \%$ & $5,25 \%$ & $5,25 \%$ & $7,25 \%$ & $7,25 \%$ \\
\hline April & $6,85 \%$ & $5,25 \%$ & $5,25 \%$ & $7,25 \%$ & $7,25 \%$ \\
\hline Mei & $6,85 \%$ & $5,25 \%$ & $5,25 \%$ & $7,25 \%$ & $7,25 \%$ \\
\hline Juni & $6,85 \%$ & $5,25 \%$ & $6,25 \%$ & $7,25 \%$ & $7,25 \%$ \\
\hline Juli & $6,85 \%$ & $5,25 \%$ & $6,75 \%$ & $7,25 \%$ & $7,25 \%$ \\
\hline Agustus & $6,85 \%$ & $5,25 \%$ & $6,75 \%$ & $7,25 \%$ & $7,25 \%$ \\
\hline September & $6,85 \%$ & $5,25 \%$ & $7,25 \%$ & $7,25 \%$ & $7,25 \%$ \\
\hline Oktober & $6,75 \%$ & $5,25 \%$ & $7,25 \%$ & $7,25 \%$ & $7,25 \%$ \\
\hline November & $6,25 \%$ & $5,25 \%$ & $7,75 \%$ & $7,25 \%$ & $7,25 \%$ \\
\hline Desember & $6,25 \%$ & $5,25 \%$ & $7,25 \%$ & $7,25 \%$ & $7,25 \%$ \\
\hline
\end{tabular}

Berdasarkan tabel di atas, rata-rata suku bunga bebas risiko per tahun adalah 6,77084444 persen, yang artinya jika investor berinvestasi pada SBI satu bulan, mereka akan memperoleh rata-rata 6,77084444 persen dari dana yang diinvestasikan per tahun. Karena data harga saham yang digunakan dalam analisis ini adalah mingguan, maka tingkat bebas risiko digunakan untuk menghitung portofolio bulanan yang ideal. Bila rata-rata bebas risiko tahunan dibagi 60 bulan, hasilnya 0,5642362342 persen per bulan.

\section{Hasil Estimasi Penelitian Statistik Deskriptif}

Hasil dari analisis saham kandidat portofolio. Dengan menggunakan spss versi 16 yang meliputi jumlah sampel (N), mean, std. deviasi, minimum dan maksimum. Selanjutnya, hasil olahan SPSS dapat di lihat pada tabel 6 berikut ini:

\section{Tabel 6 Analisis Statistik Deskriptif}

Descriptive Statistics

\begin{tabular}{|l|r|r|r|r|r|}
\hline & $\mathrm{N}$ & \multicolumn{1}{|c|}{ Mean } & \multicolumn{1}{c|}{ Std. Deviation } & \multicolumn{1}{c|}{ Minimum } & \multicolumn{1}{c|}{ Maximum } \\
\hline Excess Return to Beta & 12 & .175819689 & .1557032955 & $-1.8979368 \mathrm{E}-2$ & .5588480 \\
$\mathrm{C}_{\mathrm{i}}$ & 12 & $2.644787408 \mathrm{E} 0$ & $3.8826473330 \mathrm{E} 0$ & .0933380 & $1.3917873 \mathrm{E} 1$ \\
\hline
\end{tabular}

Dari data tersebut, diketahui bahwa $(\mathrm{N})$ terdapat 12 data, periode penelitian selama 5 tahun. Berdasarkan hasil statistik deskriptif terlihat bahwa nilai minimum ERB adalah 1.8979368 dan nilai maksimum sebesar 0.5588480 , sedangkan nilai minimum dari Ci adalah 0,0933380 dan nilai maksimum sebesar 1,3917873 dengan nilai mean dari ERB adalah 0,175819689, dan Ci yaitu 2,644787408, dengan standar deviasi untuk nilai ERB adalah 0,1447032955, sedangkan untuk nilai Ci adalah 3,8826473330.

Berdasarkan temuan Uji Statistik Nonparametrik (Wilcoxon Test), terdapat ketidaksesuaian antara dua model pembuatan portofolio secara optimal, yaitu Pendekatan Model Indeks Tunggal dengan Random. Saham yang termasuk dalam portfolio nominee ideal yaitu mempunyai nilai ERB lebih besar dari $\mathrm{Ci}$, yaitu 2. ASRI dan SMGR adalah dua saham 
tersebut.

Dengan demikian, perbedaan dapat dibuat antara dua metode konstruksi portofolio yang cukup optimal, yaitu Metode Model Indeks Tunggal dan Metode Acak. Portofolio terdiri dari saham-saham dengan nilai ERB tertinggi yaitu saham WIKA sebesar 0,559948006, ASRI dengan angka 0,185946634, seta SMGR dengan angka 0,102067459 yang terakhir mempunyi nilai ERB tertinggi.

\section{KESIMPULAN}

Berdasarkan analisis di atas, diketahui bahwa dengan model indeks tunggal, teridentifikasi tiga kandidat portofolio yang maksimal; saham portofolio kandidat adalah WIKA, ASRI, dan SMGR. Dan berdasarkan data saham yang termasuk dalam perhitungan saham LQ45 periode Januari 2013-Desember 2017, kami memilih secara acak dua kandidat portofolio optimal: ASRI dan SMGR. Komposisi atau proporsi dana yang diperoleh masingmasing saham optimal untuk pembentukan portofolio; terbesar adalah saham WIKA 0,559948006, dan yang terkecil adalah saham UNTR, dengan poin 0,559948006.

\section{DAFTAR PUSTAKA}

Afriana, T., Tarno, T., \& Sugito, S. (2017). Analisis Pembentukan Portofolio Pada Perusahaan Yang Terdaftar Di Lq45 Dengan Pendekatan Metode Markowitz Menggunakan Gui Matlab. Jurnal Gaussian, 6(2), 251-260.

Afriana, T., Tarno, T., \& Sugito, S. (2017). Analisis Pembentukan Portofolio Pada Perusahaan Yang Terdaftar Di Lq45 Dengan Pendekatan Metode Markowitz Menggunakan Gui Matlab. Jurnal Gaussian, 6(2), 251-260.

Arabi, K. (2014). Portfolio Formation: Empirical evidence from Khartoum stock exchange. International Journal of Social Sciences and Entrepreneurship, 1(9), 1-19.

Chapple, L., \& Humphrey, J. E. (2014). Does board gender diversity have a financial impact? Evidence using stock portfolio performance. Journal of business ethics, 122(4), 709723.

Dian, C. (2018). Pembentukan Portofolio Optimal Pada Beberapa Indeks Saham Menggunakan Model Markowizt. Jurnal Akuntansi Muhammadiyah, 10(2).

Gudono, A. A. R. (2018). Implementasi Strategi Aktif dan Pasif Dalam Pembentukan Portofolio Optimal Saham. Artikel Ilmiah. Universitas Negeri Yogyakarta.

Hiendarto, O., \& Indrawati, N. K. (2015). Analisis Market Overreaction Di Bursa Efek Indonesia Pada Masa 100 Hari Kerja Jokowi-JK. 3 (2). Retrieved From Jurnal Ilmiah Mahasiswa Feb Universitas Brawijaya.

Irfan, M. S. (2018). Pengaruh Variabel Makroekonomi Dan Mikroekonomi Terhadap Return Defensive Stocks Yang Terdaftar Pada Jakarta Islamic Index (JII) Periode 20142018 (Doctoral dissertation, Universitas Brawijaya).

Kusbiantono, K. (2002). Hubungan Risiko Perusahaan dan Risiko Pasar serta Pengaruhnya pada Tingkat Diversifikasi Portofolio Saham. The Winners, 3(2), 134-149.

Laksono, A. (2004). Analisis Portofolio Optimal Investasi Saham Di Bursa Efek Jakarta" Studi Komparatif Antara Stochastic Dominance Dengan Single Index Model"(Periode 1997 Sampai Dengan 2003) (Doctoral dissertation, Program Pascasarjana Universitas Diponegoro). 
Noer, M., Saribanon, N., \& Nurwulandari, A. (2017). Business Model Analysis of Natural Production Forest with Sustainable Forest Management Approach. GeografiaMalaysian Journal of Society and Space, 13(1).

Nuryana, F. (2014). Analisis Pemilihan Instrumen Investasi Bisnis Emas, Valuta Asing dan Saham. IQTISHADIA: Jurnal Ekonomi dan Perbankan Syariah, 1(2), 196-220.

Paranjape-Voditel, P., \& Deshpande, U. (2013). A stock market portfolio recommender system based on association rule mining. Applied Soft Computing, 13(2), 1055-1063.

Sakti, V. P. D., \& Surepno, S. (2018). Penilaian Harga Saham Syariah: Pengaruh Debt To Asset Rasio, Net Profit Margin, Price To Book Value Dan Economic Value Added (Studi Perusahaan Yang Terdaftar Di Jii Tahun 2015-2017). Madic.

Sari, L. R., \& Prijati, P. (2015). Perbandingan Return Saham Kompas 100 Menggunakan Model Indeks Tunggal Dan Model Random. Jurnal Ilmu dan Riset Manajemen (JIRM), 4(4).

Savitriani, M. D., \& Sugiyono, S. (2017). Pengaruh Pembentukan Portofolio Terhadap Return Dan Risiko Saham Di Perusahaan LQ45. Jurnal Ilmu dan Riset Manajemen (JIRM), 6(1).

Sunaryo, D., \& S MB, M. M. (2017). Manajemen Investasi dan Portofolio. Penerbit Qiara Media.

Zulfa, N. A. (2015). Analisis Estimasi Volatilitas Indeks Hargasaham Menggunakan Harga Tertinggi, Terendah, Pembukaan, Dan Penutupan (Studi pada Indeks Saham Sektoral di Bursa Efek Indonesia Periode 4 Maret 2013-4 Maret 2015) (Doctoral dissertation, Universitas Negeri Semarang). 